Fecha de recepción: marzo 2020 Fecha de aceptación: abril 2020 Versión final: junio 2020

\section{El ingreso de políticos outsiders a la partidocracia uruguaya}

Federico Musto Crucci ${ }^{(1)}$

Resumen: En las elecciones nacionales uruguayas de 2019 se constató la irrupción exitosa de varios políticos que se categorizan como outsiders por provenir desde fuera del sistema político. Este ascenso y su función determinante en la decisión del futuro presidente de la República es una advertencia para los partidos y los políticos. El contexto político, global y regional, las ideas que circulan y el momento actual de la comunicación y el uso de herramientas digitales han sido factores que coadyuvaron a la emergencia y al rol que tuvo este tipo de políticos en las recientes elecciones uruguayas.

Palabras clave: outsiders - comunicación - elecciones presidenciales - Uruguay.

[Resúmenes en inglés y portugués en la página 240]

(1) Maestrando en Derechos Humanos y Democratización por la Universidad Nacional de San Martín (Argentina). Licenciado en Ciencia Política por la Facultad de Ciencias Sociales de la Universidad de la República (Uruguay). Técnico en Comunicación Social por CETP-UTU (Uruguay). He participado en proyectos de investigación como asistente de investigación en el Grupo de Reforma Social de la Facultad de Ciencias Sociales (UdelaR).

\title{
Introducción
}

Uruguay comenzó su periodo electoral en junio de 2019 con las elecciones internas para seleccionar los candidatos únicos a presidente que compitieron en octubre en la primera vuelta y en noviembre en el balotaje. Fue el quinto periodo electoral bajo las nuevas reglas implementadas en la Reforma Constitucional de 1996 y donde por primera vez obtuvo la victoria el Partido Nacional. La última vez que lo consiguió fue en 1990 bajo las reglas anteriores, denominada Ley de Lemas.

Sin embargo, uno de los aspectos distintivos de estas elecciones fue la irrupción de los candidatos outsiders y su manera de comunicarse, no sólo por la cantidad y la aparición en varios partidos diferentes, sino por el éxito electoral que obtuvieron.

En el presente artículo, se presentarán los casos de Juan Sartori del Partido Nacional, Ernesto Talvi del Partido Colorado y Guido Manini Ríos por el partido Cabildo Abierto ${ }^{1}$. 
También es relevante dada la característica del sistema de partidos uruguayo. Es considerado por la ciencia política como partidocrático, es decir, que los partidos juegan un rol central tanto en la gestión de lo público como en la intermediación con la sociedad y el Estado y como actor fundamental en la selección de cuadros dentro de los partidos (especialmente para la carrera hacia la presidencia).

En este sentido, la aparición de figuras que se insertan en la política partidaria desde afuera del sistema (algunos dentro de partidos consolidados y otros creando nuevos partidos) invita a analizar con mayor detenimiento el fenómeno con una perspectiva politológica. A su vez, el artículo se centrará en observar cómo utilizaron la comunicación para erigirse como candidatos y construir su liderazgo, transmitir sus valores y competir por ser candidatos dentro de sus partidos (y luego, en caso de avanzar, por la presidencia).

\section{Elecciones uruguayas}

Desde la reforma de la Constitución en $1996^{2}$ los ciclos electorales se efectúan cada cinco años y comienzan en junio con las elecciones internas, en octubre del mismo año se renueva la totalidad del Poder Legislativo y se compite por la elección del presidente y vicepresidente (titulares del Poder Ejecutivo). En caso de no conseguir la mayoría, el último domingo de noviembre se lleva a cabo la segunda vuelta o balotaje. La competencia por las autoridades departamentales (ejecutivas y legislativas) y municipales (desde la reforma del $2009^{3}$ ) se llevan a cabo en mayo del año siguiente. En este sentido, el periodo electoral uruguayo comienza en junio y termina en mayo del año siguiente, si bien el presente ciclo electoral va de junio 2019 a mayo 2020, será considerado la etapa previa a junio y algunas consideraciones generales hacia octubre-noviembre del mismo año.

Bajo las nuevas reglas electorales se llegó a la instancia de segunda vuelta en todos los años menos en 2004, cuando el Frente Amplio obtuvo la mayoría absoluta en octubre y logró acceder al gobierno nacional por primera vez en la historia.

Luego de quince años ininterrumpidos de gobierno del Frente Amplio, en 2019 dicha fuerza política buscó retener el poder. Para lograr este objetivo, presentó, el 30 de junio del 2019, cuatro precandidatos para competir en su interna: Daniel Martínez, Carolina Cosse, Oscar Andrade y Mario Bergara. Los cuatro representaron el inicio de la renovación de liderazgo de la coalición de izquierda. Si bien los cuatro han tenido activa participación en los gobiernos anteriores (tanto a nivel nacional como departamental) la propuesta fue competir con nuevos nombres ${ }^{4}$, sin por eso soslayar la trayectoria en la política nacional. Los otros principales partidos políticos también presentaron cierta renovación en su plantel de candidatos. Sin embargo, a diferencia de los establecido por el Frente Amplio, tanto el Partido Nacional, el Partido Colorado y el novel partido Cabildo Abierto ${ }^{5}$ presentaron figuras que podrían considerarse outsiders del establishment partidario lo que generó una novedad en este periodo eleccionario y por el resultado obtenido por ellos. En el balotaje de noviembre, Luis Alberto Lacalle Pou (Partido Nacional ${ }^{6}$ ) obtuvo la victoria frente al candidato oficialista Daniel Martínez. Esto tuvo tres implicaciones importantes: i) el Frente Amplio no logró la cuarta victoria consecutiva por lo que su proceso 
de gobierno terminará el 1 de marzo de 2020, ii) el Partido Nacional volverá a liderar el gobierno nacional, la última vez lo hizo tras la victoria de Luis Alberto Lacalle Herrera (padre del flamante presidente) por el período de 1990-1995 (siendo una de las tres veces que los nacionalistas consiguieron dicha victoria durante el siglo $\mathrm{XX}$, las anteriores fueron entre 1959-1963 y 1963-1967), iii) los candidatos apoyaron a Lacalle Pou y habían recibido mayor cantidad de votos en octubre fueron outsiders (Ernesto Talvi del Partido Colorado y Guido Manini Ríos de Cabildo Abierto) ${ }^{7}$.

\section{Outsiders}

La irrupción de los políticos outsiders no es una novedad a nivel global'; sin embargo, su reciente ascenso en Uruguay, y especialmente en las elecciones de 2019, merece un análisis más profundo.

Los políticos outsiders son quienes deciden ingresar a la competencia electoral con una procedencia externa al propio sistema político (es decir, quienes se contraponen a los insiders, aquellos que cuentan con una trayectoria dentro del sistema). Ya la literatura institucionalista de la ciencia política le comenzó a prestar atención en la década de 1980 y 1990 por el creciente ascenso de estas figuras en los sistemas presidencialistas de América Latina. Miguel Carreras (2012) enuncia las consideraciones que se han elaborado al respecto, Juan Linz (1994) sostenía que el ascenso de los outsiders era un peligro para el presidencialismo y, a su vez, Scott Mainwaring (1993) argüía que los presidencialismos permitían a un individuo sin experiencia previa crear un nuevo partido y participar en las elecciones. Por su parte, Waldino Cleto Suárez (1982) esgrimió dos consecuencias perjudiciales. En primera instancia, una reducción de la eficiencia del Poder Ejecutivo por la falta de experiencia previa y, además, esto favorecía el desarrollo de un estilo personalista en el quehacer político. Por su parte, Guillermo O’Donnell (1994) plantea la posibilidad de bypassear instituciones intermedias y desarrollar formas de democracia delegativa (Carrera, 2012).

Por último, Carreras sostiene que la participación de outsiders también puede repercutir en el sistema de partidos, desestabilizándolo, por aumentar el número efectivo de partidos (si es que el nuevo político compite en partidos que hay creado él mismo). Ya ha sido largamente estudiada la "difícil combinación" entre el presidencialismo y el multipartidismo (Mainwaring, 1993) al aumentar la probabilidad de estancamiento en la relación entre el Poder Ejecutivo y el Legislativo. Además, puede afectar la volatilidad electoral (es decir la probabilidad de votar al mismo partido disminuye) y esto, según Mainwaring y Scully (1995) puede deteriorar la institucionalización del sistema de partidos (Carreras, 2012).

Los outsiders pueden ser considerados, siguiendo a Rodríguez Andrés (2016) como: i) quienes, sin tener experiencia previa, se presentan a elecciones, ii) quienes están al margen de la política tradicional y/o tienen un discurso contrario a él, buscan ser la alternativa (un vocablo anglosajón que se puede utilizar para caracterizar a este tipo de políticos es antiestablishment), iii) quienes logran triunfar a pesar de no ser favoritos y dan la sorpresa. En este sentido, los políticos outsiders pueden ser considerados como tal por dos moti- 
vos, o bien por su posición relativa frente al sistema político (es decir la dicotomía insider - outsider) o por su discurso que intente ser rupturista con el sistema de partidos y el sistema político en general (en este aspecto, la referencia es a los políticos con un discurso antiestablishment $\mathrm{o}$ incluso populistas).

No obstante lo cual, siguiendo lo establecido por Carreras (2012), se hará énfasis en la primera de las consideraciones, es decir, en su posición frente al sistema y su experiencia previa. La operacionalización es más simple dado que la propia definición de populismo o antiestablishment puede dificultar este tipo de trabajo. Además, por considerar la posibilidad de la existencia de políticos insiders que tengan ese tipo de discurso o, incluso, outsiders que no lo tengan.

Se utilizará la definición propuesta por Carreras, donde sostiene que "los políticos outsiders son candidatos que i) no han tenido una carrera previa en política o en la administración pública cuando comienza la campaña y/o ii) participan en las elecciones como políticos independientes o en asociación con nuevos partidos" (Carrera, 2012:1456) ${ }^{9}$. El autor propone dos variables para categorizar y, luego, clasificar dichos políticos, la experiencia previa y el partido por el cual se candidatean.

De su definición se generan tres posibles tipos de políticos outsiders: aquellos que no tienen experiencia previa en política y compiten en nuevos partidos son denominados full outsiders (outsiders completos, totales); quienes compiten sin tener experiencia previa pero en partidos ya establecidos son denominados como amateurs (aficionados); por último, quienes tienen experiencia previa, pero compiten en partidos nuevos se denominan mavericks (rebeldes, disidentes).

Como ya se ha mencionado, el sistema de partidos de Uruguay es caracterizado por la ciencia política como partidocrático (Caetano, Pérez Antón y Rilla, 1989). Según los politólogos uruguayos Daniel Chasquetti y Daniel Buquet (2004), el "centro gravitacional" de la democracia uruguaya son los partidos políticos. También destacan la profunda adhesión por los valores democráticos de la ciudadanía nacional.

En la elaboración de Caetano, Pérez y Rilla, la idea de concebir al sistema político uruguayo como una partidocracia se fundamenta en que la "centralidad de los partidos uruguayos como actores políticos dominantes constituye una línea de larga duración de nuestra historia y una clave configuradora de nuestra política" (1989: 21) (Chasquetti y Buquet, 2004, p. 232)

Lejos de promover una visión peyorativa del sistema político como sostiene Sartori (partidocrazia) donde supone la tiranía del partido que concentra todo el poder (1994), "la centralidad partidaria uruguaya ha sido un factor esencial para que la autonomía política, el consenso y la estabilidad democrática sean los rasgos más característicos de su sistema político en el largo plazo" (Chasquetti y Buquet, 2004, p. 233).

Los partidos han cumplido diversos roles en la sociedad y en la política nacional principalmente como intermediarios de las demandas sociales hacia la esfera gubernamental. Pero una característica fundamental (que comparte, claramente, con la mayoría de los partidos institucionalizados del mundo por su propia definición) que han detentado los partidos uruguayos es tanto la selección de candidatos como la tramitación mayoritaria 
de las carreras políticas. En este sentido, la aparición de políticos outsiders es novedosos, más aún los que no ingresan por partidos ya establecidos.

A modo general, se puede sostener que estos nuevos políticos ingresan al sistema de partidos uruguayo con un posicionamiento ideológico del centro hacia la centroderecha y derecha ${ }^{10}$. Los tres casos que se presentan a continuación se erigen como nuevos hacedores de política, promuevan una nueva forma de hacer política vis a vis la anterior manera de hacerla.

Según Rodríguez Andrés, quienes se presentan como antiestablishment se atribuyen para sí la capacidad de ser los auténticos representantes de los ciudadanos y agentes de cambio -incluso llamándose a sí mismos como salvadores de la nación, pudiendo realizar apelaciones morales al respecto- (2016). El autor plantea que este tipo de políticos que promueven la antipolítica por lo general se posicionan como extremistas hasta llegar al punto de ser abiertamente antidemocráticos. En este sentido, es importante considerar lo expresado por Boas (2011) cuando sentencia que "los tipos de mensajes que los candidatos presentan a los votantes y los medios por los cuales movilizan su apoyo tienen gran incidencia en la calidad de las nuevas democracias alrededor del mundo" (p. 41).

\section{La campaña de los outsiders: el académico, el empresario y el militar}

Cuando una persona decide insertarse en la arena política queda instalado de manera inmediata en la esfera mediática, lo que implica la centralidad de los medios de comunicación en la mediación entre los representantes y los representados. Especialmente cuando quienes intentar llegar al poder provienen desde fuera del sistema y la necesidad por hacerse conocer y divulgar sus posturas es mayor.

Este proceso se puede evidenciar de manera clave y con mayor presencia en la década de 1980, "lo que Manin denominó democracia de audiencias (...) desde la llamada 'telepolítica' hasta el uso de las redes sociales, pasando por el noticiero, entre otros géneros que acogieron y saturaron el campo de lo político" (Montero, 2018, p. 42).

Incluso esta nueva forma de considerar el vínculo entre los políticos y la opinión pública hace que su propia definición (y por ende las estrategias que se utilizan para dialogar con ella) haya mutado. Desde una opinión pública de masas, concentrada, jerárquica y unidireccional a una comunicación en red, dispersa, multidireccional, hipertextual, interactiva. Los propios sujetos que componen esa opinión pública se conciben como interactivos, ya no pasivos, sino emisores y productores de contenido (Montero, 2018:43). Las redes sociales asociadas a internet han sido el vehículo fundamental para promover este proceso $^{11}$.

Esta situación es especialmente atendida por los outsiders por provenir desde el mundo empresarial (en la mayoría de los casos) aunque influye en el mundo político en general. En este sentido, Montero expresa que:

El vínculo del discurso político con esta opinión pública en red evidentemente difiere del que los partidos tradicionales mantenían con el mundo de los 
sondeos: si la opinión pública "conversa" en múltiples plataformas, de forma interactiva, horizontal y reticular, el discurso político debe escuchar, recoger y participar en esa conversación (2018, p. 43).

Estas nuevas formas de mediatizar los discursos Slimovich (2016) plantea que se ocasiona por la crisis del broadcast (Carlón y Scolari, 2009) y la expansión de los nuevos medios. La autora utiliza el concepto digitalización de la política, es decir, la incursión de la política en los medios con base a internet.

Bajo este esquema actual de la comunicación política es que emergen los outsiders en Uruguay y se insertan en su sistema político. La manera de utilizar estas herramientas es fundamental para intentar posicionarse como competidores en las elecciones. De esta forma, a continuación, se presentan los tres políticos seleccionados, sus campañas y el uso de las redes sociales.

\section{Ernesto Talvi: el académico}

El Partido Colorado presentó seis precandidaturas de las cuales dos fueron competitivas (si bien hubo un tercer candidato con trayectoria política previa y cierto reconocimiento, José Amorín Batlle, en ningún momento tuvo reales posibilidades de ganar las internas). Por un lado, el otrora dos veces presidente de la República, Julio María Sanguinetti (1985-1990, 1995-2000) que regresó a la arena política luego de estar unos años apartados de ella y Ernesto Talvi y su grupo Ciudadanos.

Talvi es Licenciado en Economía por la Universidad de la República de Uruguay y obtuvo su doctorado en Economía por la Universidad de Chicago con una dilatada trayectoria en el mundo académico. Fue durante 21 años el Director Académico del CERES (Centro de Estudios de la Realidad Económica y Social), investigador senior no residente de la Brookings Institution en Washington DC. A su vez, fue Asesor Principal en temas macroeconómicos y financieros globales y regionales del Departamento de Investigación del Banco Interamericano de Desarrollo (BID), fue investigador en el BID y el Fondo Monetario Internacional (FMI), miembro fundador del Comité Latinoamericano de Asuntos Financieros (CLAAF) y miembro del Comité Ejecutivo de LACEA (Asociación Económica para América Latina y el Caribe $)^{12}$.

Además, en el ámbito público fue director del Departamento de Política Económica del Banco Central del Uruguay (de 1990 a 1995, durante la presidencia de Luis Alberto Lacalle Herrera por el Partido Nacional).

El 14 de agosto de 2018 lanza su precandidatura y la creación del nuevo grupo dentro del Partido Colorado, Ciudadanos. A través de las redes sociales ${ }^{13}$ (Twitter, Instagram, Facebook) busca hacerse conocerse, manifestar sus valores, sus razones de entrar en política, divulgar sus actividade, tanto mediáticas, como reuniones con personalidades y grupos de interés y visitas a diferentes ciudades, todas acompañadas de fotos de paisajes de Uruguay o bien rodeado de personas que asisten a sus eventos. 
Tanto en sus discursos como en el uso de redes sociales busca constituirse como político cercano (por ejemplo, respondiendo él mismo los tweets, expresando que no tenía community manager o apareciendo en fotos abrazado a personas), preocupado por la situación del Uruguay y con soluciones, pero también dándole importancia a los partidos políticos y a la democracia.

Uno de sus principales ejes programáticas es la educación -“volver a ser un país modelo" -, es decir, se muestra preocupado por la gestión del Estado, el control del gasto, la reforma del Estado.

Si se considera la clasificación realizada por Carreras (2012), y explicitada con anterioridad, a Ernesto Talvi se lo puede categorizar como un amateur dado que ingresa en un partido consolidado como el Colorado, pero no tiene experiencia política, en el tweet que aparece en la Figura 1 lo deja claramente establecido. Si bien tuvo un cargo en la década de 1990 fue en un puesto netamente técnico y de designación directa. Además, en mucho ámbitos ha destacado su cercanía con el expresidente Jorge Batlle (también del Partido Colorado, 2000-2005) pero desde un plano personal o de consulta. Nunca participó en elecciones ni en puesto electivos.

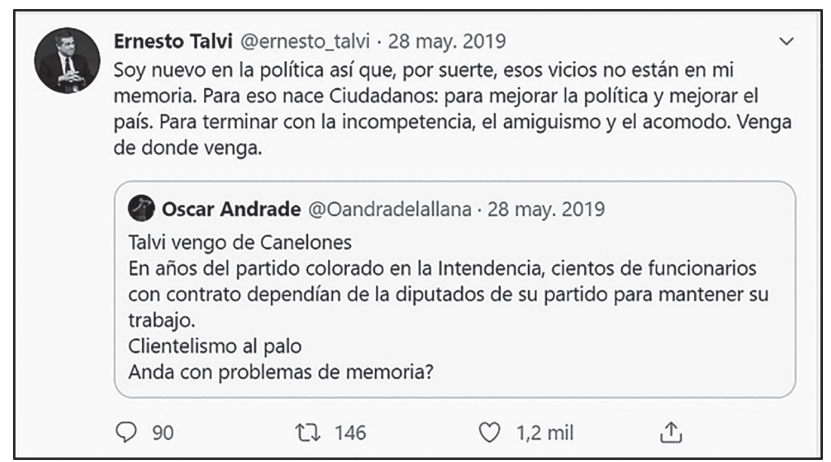

Figura 1. Captura de pantalla de tweet de @ernesto_talvi. Fuente: Twitter

Desde lo discursivo, como se muestra en uno de los tweets, se expresa como profundamente democráticos, "liberal progresista" y expresó su creencia en los partidos y en el sistema democrático. Su irrupción en política no ha sido para cambiar el sistema, sino que, como académico, volcar su conocimiento y su experiencia para mejorar el país según sus convicciones.

El resultado de la elección interna generó una doble sorpresa, no solo triunfó sobre Sanguinetti, sino que lo hizo por amplio margen (53,72\% para Talvi frente al 32,81\% del expresidente). Como candidato del Partido Colorado quedó en tercer lugar con un 12,34\%, resultó electo Senador de la República y de cara a la segunda vuelta llevada a cabo en noviembre del 
mismo año apoyó e integró la denominada Coalición Multicolor o Coalición por el cambio (fue la unión de los partidos de oposición que impulsaban la candidatura como presidente de Luis Lacalle Pou) y luego del triunfo fue confirmado como Canciller de la República.

\section{Juan Sartori: el empresario}

La irrupción de Sartori en la política nacional fue inesperada, sorpresiva y disruptiva. Si bien perdió las internas frente a quien fue electo presidente para el periodo 2020-2025, Luis Alberto Lacalle Pou, se colocó en segundo lugar, obteniendo el 20,68\% al interior del Partido Nacional (lo que representó 94.581 sufragios) y derrotando a Jorge Larrañaga, quien quedó en tercer lugar, líder de largo recorrido en filas nacionalistas, intendente de Paysandú (1990-2000), senador de la República (2000-2019), candidato a presidente (2004), candidato a vicepresidente (2009 y 2014).

Sartori es un empresario, inversionista, accionista del equipo de fútbol inglés Sunderland FC. Es Licenciado en Economía por la HEC Lausanne. Está casado con Ekaterina Rybolovleva (hija del magnate ruso Dmitri Rybolóvlev). Si bien Sartori tenía negocios en Uruguay (vinculados al agro y llegó a incursionar con su empresa en el negocio de la plantación de la marihuana estatal ${ }^{14}$ ), no era conocido públicamente. Desde muy pequeño emigró con su familia (a Francia y Suiza) y su residencia permanente no era Uruguay, de hecho, la primera vez que emitió su voto fue en el 2019.

Según la categorización propuesta por Carreras, a Sartori se lo puede ubicar dentro de los outsiders amateurs, dado que no tenía experiencia previa, pero ingresa a la competencia electoral en un partido histórica de Uruguay como el Nacional.

Por todo lo anterior su campaña tuvo tres etapas diferentes y la primera, claramente, fue la presentación en sociedad del joven empresario devenido en político. El uso de las redes fue novedoso, moderno y profesional. La primera etapa se dividió en dos, una campaña de expectativa dónde se preguntaban quién era Juan Sartori y luego la presentación como indican las imágenes de su Twitter.

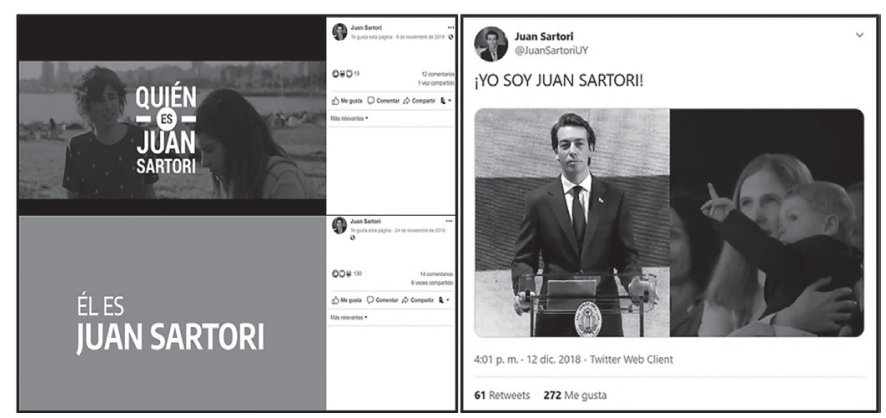

Figura 2. Captura de pantalla de tweets de @JuanSartoriUY. Fuente: Twitter. 
En la segunda etapa, con Sartori ya consolidado como precandidato e instalado en la vida pública, la campaña devino en generar propuestas, entre ellas se puede destacar la apertura al mundo, generar trabajo (prometió la creación de 100.000 puestos), medicamentos gratis para los jubilados, mejorar las gestión. Se posicionaba en su éxito como empresario para trasladarlo a la gestión pública. En todas las etapas Sartori se mostró ágil, rodeado de personas (utilizó con frecuencia el recurso de sacarse selfies con las personas que se acercan), con un manejo profesional de las redes, por las publicaciones y la planificación (por ejemplo, el constante vínculo con los internautas, la realización constante de vivos tanto en Facebook como en Instagram). Vale destacar, además, que su discurso no es, a priori, antiestablishment. La tercera y última etapa previa a las elecciones internas se puede catalogar como de campaña sucia. En efecto, las encuestas de opinión pública mostraban un fuerte ascenso en la intención de voto de Sartori (Ver Figura 3) y los analistas daban un escenario abierto frente al favorito Luis Lacalle Pou. Sin embargo, unas semanas antes de los comicios comenzaron a circular denuncias sobre fake news, llamadas a horas de la madrugada con la música de los otros candidatos, de hecho, luego de las elecciones la editora de un portal de noticias, Ecos, que había sido comprado previamente por Sartori, denunció que el comando de campaña de Sartori presionaba para realizar noticias falsas que lo favorecieran y que perjudicaran a sus contrincantes ${ }^{15}$. En medio de la situación, se acusó a Sartori de haber contratado a Juan José Rendón (conocido como JJ Rendón) asesor y politólogo venezolano a quien se responsabiliza de realizar campañas negativas y sucias ${ }^{16}$. El novel líder nacionalista confirmó que lo estaba asesorando, pero para prevenir lo que Sartori decía que era una campaña sueña en su contra. Estos entredichos coincidieron con la baja en la intención de votos y luego en una derrota frente a Lacalle Pou con una ventaja considerable. En esta etapa hubo algunas alusiones que se podrían catalogar antiestablishment dado que se colocaba por fuera de las prácticas tradicionales del sistema político y por eso, según él, era castigado y desplazado.

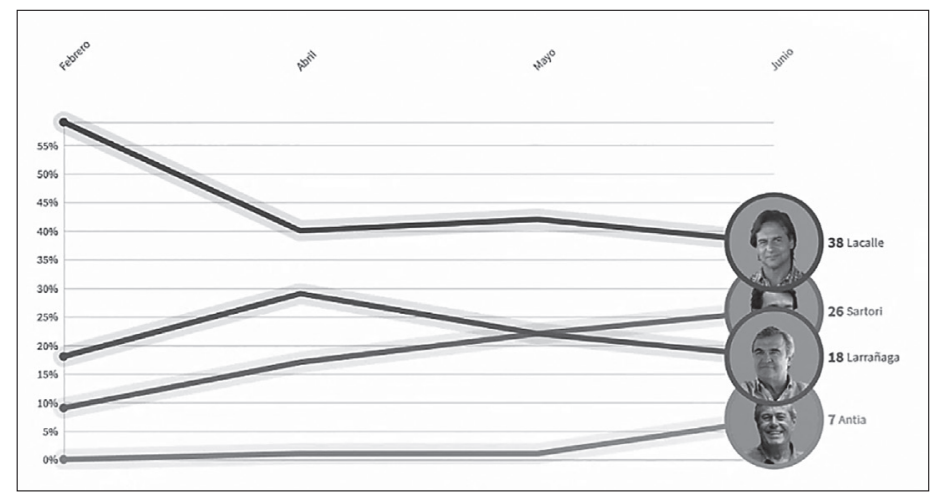

Figura 3. Evolución de la intención de voto en la interna del Partido Nacional. Fuente: La interna del Partido Nacional y la intención de voto según algunas encuestadoras (25/06/2019). Montevideo Portal. Disponible en: https://www.montevideo.com.uy/Noticias/Lainterna-del-Partido-Nacional-y-la-intencion-de-voto-segun-algunas-encuestadoras-uc722370 
Si bien no es posible determinar un nexo causal entre ambas situaciones, desde la teoría se indica que si "los votantes desaprueban la desviación del candidato de las reglas informales del juego, el castigo que ellos precisan será mucho más inmediato que el efecto similar de la opinión pública en las ventas de las empresas" (Boas, 2011, p. 51).

\section{Guido Manini Ríos: el militar}

Si la candidatura de Sartori fue sorpresiva, la de Manini Ríos fue inesperada, meteórica y controvertida. Fue candidato único por el partido Cabildo Abierto que fue inscripto en la Corte Electoral en enero de 2019 y aceptada en marzo (había sido inscrita como Movimiento Social Artiguista).

Manini Ríos viene de una familia profundamente política cuyo apellido está asociado a gran parte de la historia política del siglo XX (Pedro Manini Ríos tío abuelo y Carlo Manini Ríos, tío). Sin embargo, él eligió recorrer la carrera militar, ingresó en 1973 al Liceo Militar y llegó a detentar el grado de General (actualmente retirado). Además, es licenciado en Historia (Universidad Católica del Uruguay). Fue Director General del Hospital Central de las Fuerzas Armadas y Director Nacional de Sanidad Militar, todas las posiciones respondieron a su carrera militar.

En febrero de 2015 fue designado por José Mujica (al final de su mandato presidencial) como Comandante en Jefe del Ejército, puesto que desempeñó hasta marzo de 2019 cuando el presidente Tabaré Vázquez lo destituyó. Previamente había sido arrestado en setiembre de 2018 por criticar al ministro de Trabajo y Seguridad Social por la reforma que estaba impulsando en el sistema de retiros militares, violando el artículo 77 de la Constitución ${ }^{17}$. El 13 de marzo de 2019 fue cesado en el cargo por cuestionamientos que realizó al Poder Judicial al remitir al Ejecutivo los fallos del Tribunal Especial de Honor sobre militares condenados por delitos de lesa humanidad que habían sido sometidos a dicho tribunal. Según manifestó el portal de Presidencia, Manini Ríos expresó que "la Justicia Uruguaya en muchas oportunidades se apartó de los más elementales principios del Derecho, no dando garantías a los acusados. En definitiva, aplicó una suerte de Derecho para el enemigo"18. Al día siguiente, el 13 de marzo, Guillermo Domenech, escribano de la Presidencia desde 1990 a 2019 presentó su renuncia y comenzó a postular a Manini Ríos como presidente por su partido, el novel Cabildo Abierto. Un mes después, a inicio de abril se anuncia, por los medios tradicionales, que será candidato y no por sus redes sociales. Sus primeros posteos post aceptación son imágenes en reuniones pequeñas en el interior del país, ya como candidato a presidente.

Teniendo en cuento lo expresado por Carreras (2012) y considerando la trayectoria de Manini Ríos, su actividad pública ha sido a través de la carrera militar (regida por la Ley Orgánica Militar ${ }^{19}$, lo comprendido en la Constitución Nacional, entre otras disposiciones vigentes), con las lógicas de ascensos y de mando, con la imposibilidad de tener una vida política. Si bien tuvo visibilidad pública, la más alta en la esfera del Ejército como el de Comandante en Jefe, no se podría decir que tenía experiencia política. A su vez, comenzó a participar en un partido nuevo, por ende, se considera un full outsider. Sin 
embargo, si se entendiese que por su trayectoria militar es un candidato con experiencia previa, entonces, Manini Ríos sería un outsider de tipo maverick.

En su discurso, a Manini se lo puede considerar en primera instancia como artiguista ${ }^{20}$. Tanto su persona, como el partido en general resaltan la figura de Artigas (ver Figura 4). A su vez, bregaba por recuperar los valores tradicionales de que modelaron la patria, como la honestidad, la dignidad, la cultura del trabajo, la familia.

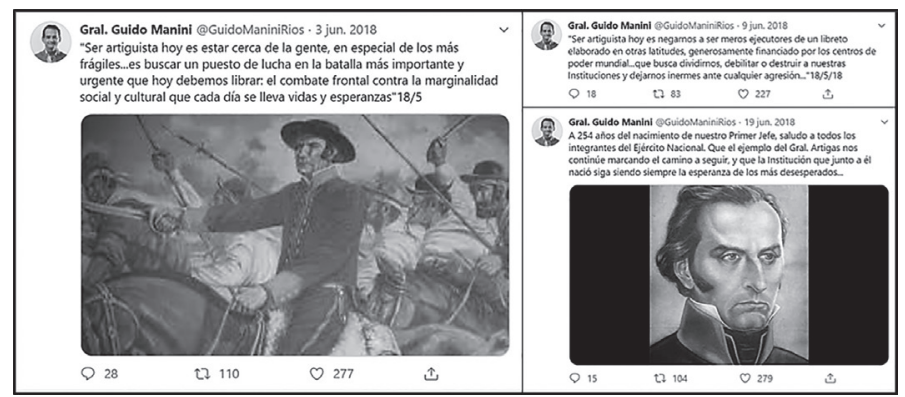

Figura 4. Captura de pantalla de tweets de @GuidoManiniRios. Fuente: Twitter

También se mostraba preocupado por la seguridad. En ese sentido, su figura se construyó en base a su liderazgo, su capacidad de mando y de firmeza (por su pasado militar y por el enfrentamiento que tuvo con el presidente, lo que fue destacado como una muestra de dignidad de su parte). Además, en su relato siempre se posicionó del lado de los más humildes, de los más necesitados. Fundamentalmente el uso de las redes sociales fue para promocionar reuniones futuras y mostrar imágenes de las ya realizadas y la recorrida que hizo por el país ${ }^{21}$. El estilo de comunicación daba la sensación de amateurismo, con una estética poco cuidada, mostrando austeridad (que es coherente con su discurso) y con ello cercanía a los más humildes. Esto se evidenció en una transmisión en vivo realizado por Facebook para comunicarse con sus seguidores. Esta apreciación, lejos de ser una crítica, puede ser una estrategia muy efectiva. ${ }^{22}$

A modo de resumen, en la Tabla 1 se sintetiza cada categoría propuesta por Carreras y se ubica en cada una de ellos a los políticos analizados. Queda una categoría de outsider sin completar, el maverick (político con experiencia que crea un nuevo partido). Es posible hipotetizar que el costo de romper con un partido y fundar uno nuevo parece bastante alto en el sistema de partidos uruguayo ${ }^{23}$ (por lo menos hasta ahora). Además, dos de los tres nuevos jugadores del sistema optaron por ingresar a partidos tradicionales para lograr lo cambios desde dentro del sistema, sabiendo los incentivos que genera competir vía partidos institucionalizados. De esta manera, la experiencia de Manini Ríos y su éxito, genera un interés especial en la trayectoria que tomará su carrera política, así como también el sistema de partidos y político en general. 


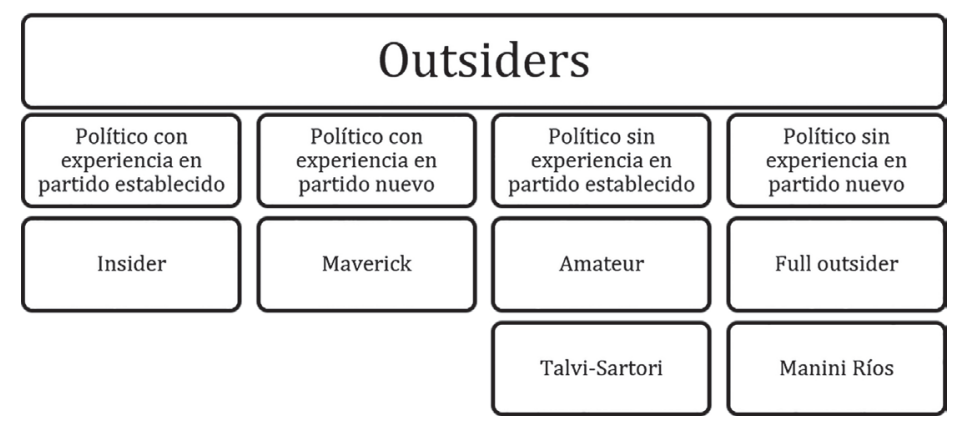

Tabla 1. Clasificación de Talvi, Sartori y Manini Ríos según las categorías de outsiders. Fuente: Elaboración propia en base a Carreras (2012).

\section{Conclusiones}

Uruguay fue considerada por mucho tiempo por su excepcionalidad democrática, el apego a los valores democráticos y la creencia en los partidos políticos como mediadores de las demandas sociales (Chasquetti y Buquet, 2004). Las nuevas innovaciones en la tecnología que repercutieron en la comunicación, el cambio en la concepción de la comunicación, en qué comunicar, cómo y a quién, ha generado impactos en la realidad, en lo cotidiano y en la política.

El ciclo electoral de 2019 en Uruguay estuvo mediado por estas situaciones y por un contexto regional y global desafiante para sostener aquella excepcionalidad. Es preciso plantear la posibilidad de que en este proceso electoral la partidocracia haya sido testeada y puesta a prueba sobre su capacidad de filtrar y tamizar aquellas voces contrarias al buen funcionamiento democrático.

Si bien en este artículo solo se presentaron tres de los nuevos políticos que aparecieron por primera vez en una contienda electoral y en la etapa previa a la elección interna (es decir, queda abierta la posibilidad de profundizar el análisis una vez completado el ciclo electoral en mayo de 2020 con las elecciones departamentales y municipales y asumidas las nuevas autoridades el 1ro de marzo de 2020), viene existiendo un intento de renovación de la política uruguaya desde el centro del espectro ideológico hacia la derecha vía outsiders y la utilización que hacen ellos de las redes sociales, la forma de vincularse con los receptores y la capacidad de bypasear los medios tradicionales de comunicación .

Hasta las elecciones internas no se registraron discursos antidemocráticos o iliberales aunque sí hubo apelaciones que buscaban restringir de derechos ${ }^{24}$ (se llamó a un prereferendum con el fin de derogar la Ley Trans - $\mathrm{n}^{\circ} 19.684-$, conjuntamente con las Elecciones Nacional se plebiscitó una Reforma Constitucional en materia de seguridad pública denominada "Vivir Sin Miedo", se evidenció un creciente discurso en torno a recortar el 
gasto público -y el gasto público social, fundamentalmente-, se cuestionó severamente las tres períodos de gobierno del Frente Amplio, denunciando clientelismo, despilfarro y corrupción. De hecho, una frase acuñada por Cabildo Abierto y utilizada durante toda la campaña fue "se terminó el recreo". Ciertamente, hubo un crecimiento claro del discurso conservador en Uruguay (sin llegar a extremos, más allá de los puntualizados).

En definitiva, el resultado final de las elecciones parece seguir la tendencia histórica, ya que ganó uno de los partidos tradicionales y el presidente electo es un político, no solo de carrera, sino proveniente de una de las familias políticas más importantes de Uruguay (Lacalle Pou es bisnieto de Luis Alberto de Herrera, histórico dirigente del Partido Nacional y su padre Luis Alberto Lacalle Herrera fue presidente de la República entre otros cargos). Aún así, lo realmente novedoso fueron los outsiders, especialmente por la importancia que tuvieron en cuanto a votos recibidos y porque su apoyo a la fórmula del Partido Nacional fue determinante para su victoria. Esta situación plantea un desafío para la academia y para la política en general, no tenerlos en cuenta y seguir pensando bajos los esquemas anteriores sería no estar observando los fenómenos actuales que están emergiendo y se están desarrollando en Uruguay.

\section{Notas}

1. Si bien hubo otros políticos que pueden ser considerados outsiders como el caso de Edgardo Novick por el Partido de la Gente o Gustavo Salle Lorier por el Partido Verde Animalista, los enunciados anteriormente son los casos exitosos.

2. El sistema electoral fue modificado con la nueva Carta Magna donde se instaló un sistema de balotaje que exige en primera vuelta obtener más del 50\% de los votos para ganar las elecciones, es decir, obtener la mayoría absoluta. En caso de no llegar a esa cantidad de sufragios, la Presidencia de la República se debe decidir en una segunda vuelta entre los dos candidatos más votados, donde rige la mayoría simple

3. Desde las elecciones de 2010 se inauguró un tercer nivel de gobierno, los municipios, donde se eligen, alcaldes y concejales.

4. Desde 1990, donde el Frente Amplio presentó a Líber Seregni (histórico dirigente, fundador de la fuerza política en 1971), por primera vez no se presentaban algunos de los dirigentes con más antigüedad e importancia de los últimos años: Tabaré Vázquez, José Mujica o Danilo Astori.

5. El Partido Nacional y Colorado son los históricos partidos políticos de Uruguay que hunden sus raíces en el siglo XIX y han sido activos protagonistas de la historia política nacional. En 1971, con el surgimiento y el éxito electoral del Frente Amplio se empieza a considerar el fin del bipartidismo en Uruguay. Por su parte, Cabildo Abierto es de los partidos de más reciente creación que data de principio del 2019.

6. Lacalle Pou contó con el apoyo de su partido, el Partido Nacional, pero logró recibir el apoyo de los sectores opositores al Frente Amplio y formar una amplia coalición con el Partido Colorado, Cabildo Abierto, Partido Independiente y Partido de la Gente. Si bien la victoria fue más ajustada de lo que preveían las encuestas (la diferencia fue de 37.042 
sufragios, lo que representa el 1,58\%) el apoyo explícito de los líderes y militantes de las otras fuerzas que integraron la coalición fue fundamental para su victoria.

7. Los otros dos líderes que completaron la coalición fueron Pablo Mieres del Partido Independiente (político con experiencia, fue varias veces candidato a presidente y ocupó una banca en el Senado en el período 2015-2020) y Edgardo Novick del Partido de la Gente (empresario devenido en político, que compitió en mayo de 2015 por la Intendencia de Montevideo como outsider (Musto, 2018) y continuó con su carrera política)

8. Es posible vincular el ascenso de los outsiders en el contexto de lo que Acosta (2019) enuncia como una crisis de representación de los partidos políticos en la denominada democracia centrada en los medios (siguiendo a Manini, 1992; Vallés, 2010). La autora plantea que "el político se comunica de manera personalizada con el electorado a través de los medios que desempeñan una función axial. Nos encontramos, en efecto, en una era en la que los medios de comunicación tradicionales han entrado también en crisis y ha emergido un nuevo sistema mediático con base en internet, definido como un hipermedio (Carlón, 2016)" (Acosta, 2019:3).

9. Traducción propia. En el original: "political outsiders are candidates who (a) have not had a previous career in politics or public administration when the campaign starts and/ or (b) participate in the elections as political independents or in association with new parties" (Carrera, 2012:1456).

10. Si bien excede a los propósitos del presente artículo, es menester realizar un análisis de los discursos que han esgrimido a lo largo de la campaña con el propósito de entender cómo se relacionan con el sistema político. Como se dijo anteriormente, los outsiders pueden ser antiestablishment, pero no necesariamente.

11. Según algunos autores como Blumler y Kavanagh (1999), la comunicación política de la segunda mitad del siglo XX se dividía en tres: i) la dominada por los partidos políticos (desde el fin de la SGM hasta 1960), ii) desde los ‘60 la era de la televisión, iii) la era digital (Enli, 2017). El propio autor sostiene que a partir del inicio de la década de 2010 ha surgido una nueva fase, la cuarta, denominada la era de las redes sociales "which represents a new shift in the power balance between politicians and editorial media; as a direct channel to the voters, social media returns us to the 'golden age of the parties'(...) the parties have been replaced by the campaign" (Enli, 2017, p. 52)

12. Disponible en: http://caets2018.aniu.org.uy/wp-content/uploads/2018/05/2018-_05CV-E.-Talvi_Espa\%C3\%B1ol.pdf

13. El uso de las redes sociales será clave para los outsiders, siguiendo a Enli (2017) "social media is the latest fascination of political communication strategists, particularly during election campaigns. While television and newspapers remain dominant sources of news in general, social media has become an increasingly important source for political news in particular" (p. 50).

14. Disponible en: https://www.busqueda.com.uy/nota/sartori-gano-mas-de-us-50-millones-con-la-marihuana

15. Disponible en: https://www.sarandi690.com.uy/2019/07/09/portal-ecos-sartori-herrera/ 16. Disponible en: https://www.elobservador.com.uy/nota/sartori-admitio-que-contrato-a-asesor-en-campana-sucia-es-el-mas-indicado-para-defenderme--20196139118

17. En el inciso $4^{\circ}$ del mencionado artículo se establece que: “(...) los militares en acti- 
vidad, cualquiera sea su grado (...) deberán abstenerse, bajo pena de destitución e inhabilitación de dos a diez años para ocupar cualquier empleo público, de formar parte de comisiones o clubes políticos, de suscribir manifiestos de partido, autorizar el uso de su nombre y, en general ejecutar cualquier otro acto público o privado de carácter político, salvo el voto" (Constitución de la República, artículo 77). Recuperado de: https://www. impo.com.uy/bases/constitucion/1967-1967/77

18. Disponible en: https://www.presidencia.gub.uy/comunicacion/comunicacionnoticias/ejercito-ejecutivo-vazquez

19. Disponible en: https://www.impo.com.uy/bases/leyes/19775-2019

20. Referido a quienes promueven las ideas y valores de José Gervasio Artigas (1764-1850) 21. Siguiendo a Enli (2017) las redes sociales han crecido en escala y alcance, aunque no han reemplazado completamente a medios tradicionales para la comunicación política (debates, publicidad, visitas puerta a puerta, las noticias, las conferencias de prensa) aunque todas estas actividades tienen impacto en las redes sociales como Twitter Facebook, Instagram 22. Tomando lo expuesto por Enli (2017) en referencia al estilo de directo y amateur de Donald Trump: "this is not to say that this kind of amateurishness is ineffective or inferior as strategic communication. There is a rhetorical strength in this voice that responds to the ideal of authenticity of the speaker (Enli, 2015). By not even attempting the guise of professionalism using digital media staffers or communication experts, that is, Donald Trump made a statement regarding his positioning as a genuine outsider" (56)

23. Tal vez, algunos ejemplos en la historia reciente sea la experiencia de Hugo Batalla en 1989 y la fundación del Nuevo y el de Pablo Mieres en 2002 con la escisión del propio Nuevo Espacio, cuando este pasó a formar parte del Frente Amplio, y la creación del Partido Independiente.

24. El Cabildo Abierto es un caso para atender teórica y académicamente por lo que fue aglutinando en torno al partido y su líder Manini Ríos, se vincularon grupos de jóvenes neonazis, hubo comentarios denigrantes para la mujer, hay militares vinculados con la última dictadura civil-militar y relacionado con casos de tortura, voces que alentaban volver a los "escuadrones de la muerte", entre otras. Todos los casos fueron desestimados y tomados como casos aislados por parte de las autoridades del partido.

\section{Bibliografía}

Acosta, M. (2019). Campañas electorales y plataformas digitales. La precandidatura de Alberto Fernández en Facebook. Question, 1 (64). Disponible en: https://doi. org/10.24215/16696581e208

Boas, T (2011). Variedades de campañas electorales. Contagio del éxito y campañas presidenciales en América Latina. Politai: Revista de Ciencia Política, 2 (3), 41-72. Disponible en: https://dialnet.unirioja.es/servlet/articulo?codigo $=5496027$

Carreras, M. (2012). The Rise of Outsiders in Latin America, 1980-2010: An Institutionalist Perspective. Comparative Political Studies, 45 (12). Disponible en: https://escholarship. org/content/qt4992q679/qt4992q679.pdf 
Chasquetti, D. y Buquet, D. (2004). La democracia en Uruguay: una partidocracia de consenso. Politica, 42, 221-247. Disponible en: https://www.redalyc.org/pdf/645/64504211.pdf

Enli, G. (2017). Twitter as arena for the authentic outsider: exploring the social media campaigns of Trump and Clinton in the 2016 US presidential election. European Journal of Communication, 32(1), 50-61.

Montero, A.S (2018). Gestionar la duda. La interpelación al paradestinatario en el discurso de Cambiemos (Argentina). Revista Mexicana de Opinión Pública 13 (25), 41-61. Disponible en: http://www.scielo.org.mx/pdf/rmop/n25/2448-4911-rmop-25-41.pdf

Musto, F. (2018). El discurso de Edgardo Novick: ¿renovación de la derecha uruguaya en clave neoliberal? (Tesis de licenciatura). Facultad de Ciencias Sociales, Universidad de la República. Disponible en: https://www.colibri.udelar.edu.uy/jspui/handle/20.500.12008/19040

Rodríguez Andrés, R. (2016). El ascenso de los candidatos outsiders como consecuencia de las nuevas formas de Comunicación Política y la desafección ciudadana. Comunicación y Hombre 12, 73-95. Disponible en: https://www.redalyc.org/pdf/1294/129446703005.pdf Slimovich, A. (2016). La digitalización de la política y la vuelta de lo televisivo. El caso de los candidatos argentinos en Facebook. Revista de Comunicación 15, 111-127. Disponible en: https://revistadecomunicacion.com/article/view/1243/1067.

\begin{abstract}
In the Uruguayan national elections of 2019, the successful emergence of several politicians who are categorized as outsiders to come from outside the political system was confirmed. This rise and its determining role in the decision of the future president of the Republic is a warning for parties and politicians. The global and regional political context, the ideas that circulate and the current moment of the communication and the use of digital tools have been factors that contributed to the emergency and the role that this type of politicians played in the recent Uruguayan elections.
\end{abstract}

Keywords: outsiders - communication - presidential elections - Uruguay.

Resumo: Nas eleições nacionais uruguaias de 2019 foi confirmado o êxito de vários políticos categorizados como outsiders cuja origem está fora do sistema político. Esta ascensão e seu papel determinante na decisão do futuro presidente da República é um alerta para políticos e seus partidos. O contexto político, global e regional, as idéias que circulam, o momento atual da comunicação e o uso de ferramentas digitais foram fatores que contribuíram para a emergência e o papel que esse perfil de político desempenhou nas recentes eleições no Uruguai

Palavras-chave: outsiders - comunicação - eleições - Uruguai.

[Las traducciones de los abstracts fueron supervisadas por el autor de cada artículo] 